\title{
Characterisation of artificial defects in CFRP and GFRP sheets designed for energy applications using active thermography
}

\author{
by C. Maierhofer ${ }^{1}$, R. Krankenhagen ${ }^{1}$, M. Röllig ${ }^{1}$, B. Rehmer ${ }^{1}$, M. Gower ${ }^{2}$, G. Baker ${ }^{2}$, M. Lodeiro ${ }^{2}$,

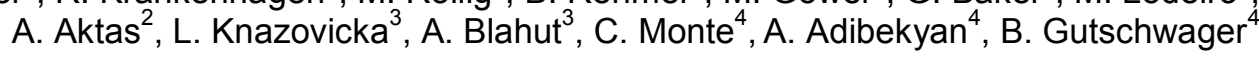 \\ ${ }^{1}$ Federal Institute for Materials Research and Testing (BAM), Unter den Eichen 87, 12205 Berlin, Germany, \\ christiane.maierhofer@bam.de \\ ${ }^{2}$ NPL National Physical Laboratory, Materials Division, Hampton Road, Teddington, Middlesex, TW11 OLW, UK, \\ Michael.Gower@npl.co.uk \\ ${ }^{3} \mathrm{CMI}$ Czech Metrological Institute, ČMI OI Praha, Radiová 3, 10200 Praha 10, Czech Republic, \\ Iknazovicka@cmi.cz \\ ${ }^{4}$ PTB Physikalisch Technische Bundesanstalt, Abbestrasse 2 - 12, 10587 Berlin, Germany \\ christian.monte@ptb.de
}

\begin{abstract}
The increased use of fibre-reinforced plastic (FRP) composites for improved efficiency and reliability in energy related applications e.g. wind and marine turbine blades, nacelles, oil and gas flexible risers, also increases the demand for innovative non-destructive testing technologies. Thus, in order to achieve increased acceptance of suited and optimized non-destructive testing (NDT) methods in industry, the European Metrology Research Programme (EMRP) project ENG57 Validated Inspection Techniques for Composites in Energy Applications (VITCEA) deals with the development and validation of innovative NDT technologies. In this contribution, results concerning thermographic investigations at test specimens during tensile loading and active thermography testing after tensile loading are presented. Additionally, the determination of the optical properties (relative transmittance and directional spectral emissivity) of CFRP and GFRP test specimens is described.
\end{abstract}

\section{Introduction}

The aim of the EMRP project VITCEA is to encourage industry adoption and the realisation of the most promising novel NDT techniques, such as microwave, active thermography, laser shearography and phased array/aircoupled ultrasonics, thus enabling the increased use of FRPs for energy applications [1]. This will be achieved through the provision of operational procedures that are based on the comprehensive evaluation and development of each technique for detecting typical defects in composites that are used in wind, wave, tidal, oil and gas and transport sectors.

For active thermography, experimental investigations using different excitation sources and time/amplitude profiles for a wide range of defects and materials are scheduled. Thermographic investigations of natural defects like delaminations and impact damage are performed during as well as after loading of the test specimens. The results will provide guidance on the most appropriate selection of inspection parameters and the limitations of the technologies. In addition, theoretical anisotropic two dimensional and three dimensional non-steady heat transfer models will be developed based on known and measured thermal and optical properties. This will be combined with appropriate defect and excitation source thermal simulations which will be solved numerically using finite element analysis and validated by comparison with experimental results. The main innovation of these investigations is to obtain defect information with highest accuracy and resolution by considering well known material parameters in combination with optimised data analysis procedures.

For obtaining quantitative information about the defect structures using thermographic testing, the optical as well as the thermal properties of the material without defect have to be determined. The optical properties should include information about the emissivity and the transmissivity of the material; thermal properties comprise the thermal conductivity, specific heat capacity and mass density. In this contribution, the determination of the relative transmittance and of the directional spectral emissivity as a function of wavelength is described.

The thermographic inspection of CFRP and GFRP test specimens during tensile loading or impact damage can provide information about the types of damage already during the damaging process [2-5]. In [3], thermography was combined with acoustic emission for the investigation of static load in unidirectional carbon fibres laminates subjected to axis and off-axis static tensile loads. Temperature increases could be correlated to acoustic emission signals concerning fibre breaking during loading and disbonding/interface failure when the sample failed. But in [3], no correlation could be found for matrix breaking. In the referred paper, no information was given on the applied load or strain.

In [4], microscopic and macroscopic damage evolution was observed during tensile loading using three different full field measurement techniques: digital image correlation, thermography and x-ray tomography. This combination of methods provided information of some damage features like the location and distribution of defects, failure mode and the influence of the initial anisotropy. In [4], $2 \mathrm{~mm}$ thick CFRP test samples with dimensions of $250 \mathrm{~mm} \times 25 \mathrm{~mm}$ and fibre orientations of $[0 / 90]_{6}$ used for axis loading and of $[+45 /-45]_{6}$ for off-axis loading were investigated. For axis loading, a 


\subsection{1/qirt.2016.076}

total displacement of $2.55 \mathrm{~mm}$ was obtained at a load of $47 \mathrm{kN}$, while for off axis loading a maximum displacement of 16 $\mathrm{mm}$ was obtained at $12 \mathrm{kN}$. During the initial loading, the thermograms show a homogeneous temperature distribution. During axis loading, hot spots are appearing which are related to fibre cracks. These are appearing more frequently at higher loads. For axis loading, the failure occurred in a sudden total crack of the sample with a high increase in the temperature of the sample demonstrating the brittle behaviour. For off axis loading, the sample showed a ductile behaviour with a temperature increase around the damage already before failure. The failure was induced by fibre matrix debonding and delamination between the plies, which finally lead to fracture.

Up to now, only little information is available about the investigation of the damage processes during static tensile load of GFRP structures using thermography. In [6] the thermoelastic behaviour of biaxial GFRP under stepwise increased tension was observed. Beginning at a tensile load of $250 \mathrm{MPa}$ a temperature increase due to macroscopic damages was detected correlated to long lineshaped thermal signatures. Libonati and Vergani [7] investigated GFRP sheets (UD and biaxial) during tensile load in different orientations (in relation to the fibre orientation), for which they found a very different thermoelastic behaviour. But the spatial extent of damaged areas was not discussed in detail.

Within the VITCEA project, static tensile load tests were used to generate artificial defects in test specimens made of CFRP and GFRP with different fibre orientations, matrix materials and geometries (thickness). In this contribution, some selected results are presented. These include thermographic observations during the tensile load of GFRP test specimens as well as thermographic characterisation of the damages afterwards in GFRP and CFRP test specimens. Results of both methods are correlated to each other and are discussed.

\section{Test specimens}

CFRP and GFRP quasi-isotropic laminates with thicknesses of about 2.5 and 5 to $6 \mathrm{~mm}$ were processed in an autoclave with documented temperature and pressure profiles. For GFRP, different matrix systems consisting of two types of epoxy (MTM 28 epoxy resin black pigmented and Prime 20LV epoxy resin) and one thermoplastic (PA12) were used. For each plate, the plies were arranged achieving a quasiisotropic fibre orientation. The thickness of the plates, used prepregs and number of layers and fibre orientations of each plate are summarized in table 1. All plates had a size of $240 \times 60 \mathrm{~mm}^{2}$. Some of these sheets were damaged with impact loads (not discussed here) and some with tensile loads. For tensile load, an initial reduction of the cross section was introduced by milling notches with a width of $5 \mathrm{~mm}$ and with different remaining wall thicknesses (for the individual remaining wall thicknesses of the notches, see table 1). It was intended that during tensile load, delaminations parallel to the surface would start at the bottom of the notches, see figure 3.a. In table 1, the parameters of the test specimens used for the thermographic investigations described below are highlighted in grey. The tensile load experiments were observed and discussed for the GFRP samples AFPD, $1 \mathrm{AFPC}$ and 2AFPC. Active thermography experiments were performed for the same GFRP samples and for the CFRP samples AFMF, 1AFMG and 2AFMG.

Table 1. Parameters of the laminates used for optical and thermographic investigations

\begin{tabular}{|c|c|c|c|c|c|}
\hline Plates & $\begin{array}{l}\text { Thickness } \\
\text { in } \mathrm{mm}\end{array}$ & $\begin{array}{l}\text { Remaining } \\
\text { wall } \\
\text { thickness of } \\
\text { notch in } \mathrm{mm}\end{array}$ & Prepreg material & $\begin{array}{l}\text { No. of layers and } \\
\text { orientation }\end{array}$ & $\begin{array}{c}\text { Diffusivity in } \\
\mathrm{mm}^{2} / \mathrm{s}\end{array}$ \\
\hline AFMF & $2.4 \pm 0.2$ & $1.3 \pm 0.1$ & \multirow{3}{*}{$\begin{array}{l}\text { Gurit SE84LV carbon fibre } \\
\text { epoxy UD prepreg } \\
\text { T700 fibre }\end{array}$} & \multirow{3}{*}{$\begin{array}{l}8 \text { and } 16 \text { ply QI lay-up } \\
{[+45 / 0 /-45 / 90]_{(2) s}}\end{array}$} & \multirow{3}{*}{$0.0039 \pm 0.0002$} \\
\hline 1AFMG & $4.8 \pm 0.2$ & $2.5 \pm 0.1$ & & & \\
\hline 2AFMG & $4.8 \pm 0.2$ & $0.9 \pm 0.1$ & & & \\
\hline 1AFSN & $6.0 \pm 0.2$ & $4.5 \pm 0.1$ & \multirow{2}{*}{$\begin{array}{l}\text { MTM } 28 \text { epoxy resin black } \\
\text { pigmented glass fibre } \\
\text { system MTM28-1B/1062- } \\
\text { 192-30\%/RW }\end{array}$} & \multirow{2}{*}{$\begin{array}{l}40 \text { layers }[+45 / 0 /-45 / 90]_{5 s} \\
\text { lay-up }\end{array}$} & \multirow[b]{2}{*}{$0.0031 \pm 0.0002$} \\
\hline 2AFSN & $6.0 \pm 0.2$ & $2.5 \pm 0.1$ & & & \\
\hline AFPD & $3.2 \pm 0.2$ & $1.7 \pm 0.1$ & \multirow{3}{*}{$\begin{array}{l}\text { Prime } 20 \text { LV epoxy resin, } \\
\text { Glass GFRP20LVI } \\
\text { quadraxial Formax } \\
\text { FGE111 }\end{array}$} & \multirow{3}{*}{$\begin{array}{l}5 \text { layers of fabric } \\
0 /-45 / 90 /+45 \text { and } 8 \text { layers } \\
\text { of fabric 0/-45/90/+45 } \\
\text { warp fibre direction along } \\
\text { the longitudinal axis }\end{array}$} & \multirow{3}{*}{$0.0026 \pm 0.0002$} \\
\hline 1AFPC & $5.0 \pm 0.2$ & $3.5 \pm 0.1$ & & & \\
\hline 2AFPC & $5.0 \pm 0.2$ & $1.6 \pm 0.1$ & & & \\
\hline 1AFPL & $5.2 \pm 0.2$ & $3.6 \pm 0.1$ & \multirow[t]{2}{*}{$\begin{array}{l}\text { GFRP Glass PA12 QI } \\
\text { layup UD prepreg }\end{array}$} & \multirow{2}{*}{$\begin{array}{l}16 \text { plies of polyamide-12 } \\
\text { glass fibre prepreg } \\
- \text { stacking sequence is } \\
{[+45 / 0 /-45 / 90]_{2 \mathrm{~s}}}\end{array}$} & \multirow{2}{*}{$0.0026 \pm 0.0002$} \\
\hline 2AFPL & $5.2 \pm 0.2$ & $1.6 \pm 0.1$ & & & \\
\hline
\end{tabular}

Already before tensile load, for the investigation of the homogeneity and for the determination of the thermal diffusivity, some of the test specimens were investigated with flash thermography. As some of the GFRP test specimens are partially translucent within the optical spectrum of the flash lamps, these were blackened at the front side before the tensile load tests using a liquid rubber spray. For the flash thermography investigations afterwards, all partially translucent GFRP test specimens were blackened at both sides. As the surface of the Prime 20LV epoxy resin GFRP test specimen is relatively rough, it was not possible to remove the rubber foil. 


\subsection{1/qirt.2016.076}

In addition to the materials described in table 1, the relative transmittance was also determined for GFRP with crossply $0 / 90$ fibre orientation and HexPLy 913 epoxy matrix.

\section{Characterisation of optical properties}

\subsection{Experimental set-up}

Test samples of the CFRPs and GFRPs without defects with a thickness of $5 \mathrm{~mm}$ were fabricated to investigate the optical properties of the materials. The knowledge of the transmittances and emissivities of the materials are required for the calculation of the radiation transport within the sample and the simulation of the active thermography experiments later on. In a first step the materials were investigated for their residual transmittance. The transmittance was determined in a setup intended for directional transmittance measurements. The samples were directionally illuminated and a limited solid angle $(0.05 \mathrm{sr})$ of the transmitted radiation was recorded. Consequently the magnitude of the recorded signal depends largely on the varying scattering properties of the samples and the thickness. So only a relative transmittance can be given. Nevertheless the spectral limits of the residual transmittance are clearly visible. Subsequently the emissivities of the non-transparent opaque samples were determined at PTB's emissivity setup in air. The setup is described in detail elsewhere [8]. Briefly, the spectral radiances of the samples at a specific temperature are measured with respect to the spectral radiance of a blackbody at known temperature. The samples are mounted in a temperature controlled hemispherical enclosure with known emissivity of the interior walls. By knowing the temperatures of samples, enclosure, blackbody and spectrometer the directional spectral emissivities of the samples can be determined from the measurements. Directional spectral measurements at angles from $10^{\circ}$ to $70^{\circ}$ were performed at sample temperature of $25^{\circ}$ in the wavelength range from $5 \mu \mathrm{m}$ to $25 \mu \mathrm{m}$.

\subsection{Results}

The relative transmittance of the different materials is shown in figure 1 . The CFRP test specimens as well as the GFRP test specimen with black pigments (GFRP MTM 28) showed no transmittance in the range from $1.3 \mu \mathrm{m}$ to $25 \mu \mathrm{m}$ whereas the three GFRP test specimens showed some residual transmittance in the range from 1.3 to $2.8 \mu \mathrm{m}$ but no significant transmittance at wavelengths longer than $2.8 \mu \mathrm{m}$.

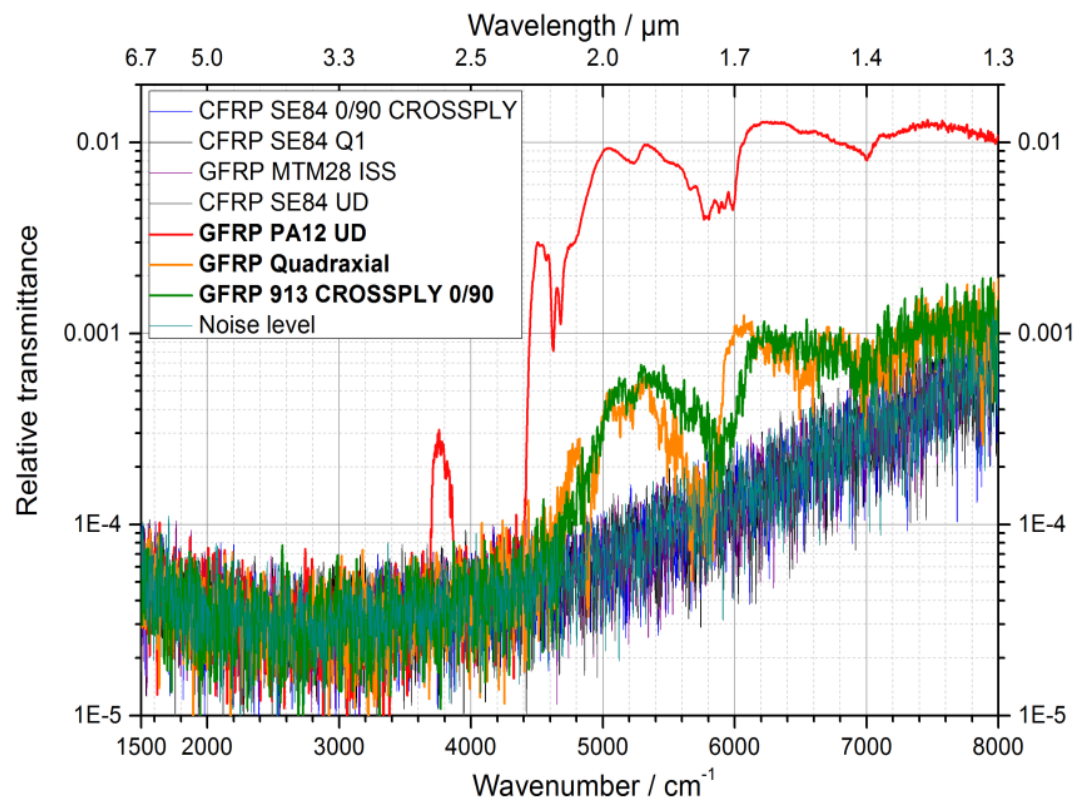

Fig. 1. Relative spectral transmittances of the CFPs and GFPs at $25{ }^{\circ} \mathrm{C}$ in the wavelength range from $1.3 \mu \mathrm{m}$ to $6.7 \mu \mathrm{m}$

The directional spectral emissivities of GFRP MTM28 recorded under angles of observation from $10^{\circ}$ to $70^{\circ}$ are shown in figure 2.a. An overall emissivity of about 0.95 at near normal observation and a typical decrease to lower values at larger angles of observation was found. The directional spectral emissivity of CFRP SE84 shown in figure 2.b is slightly lower ranging from 0.83 to 0.94 for near normal observation but also decreasing towards larger angles of observation. 


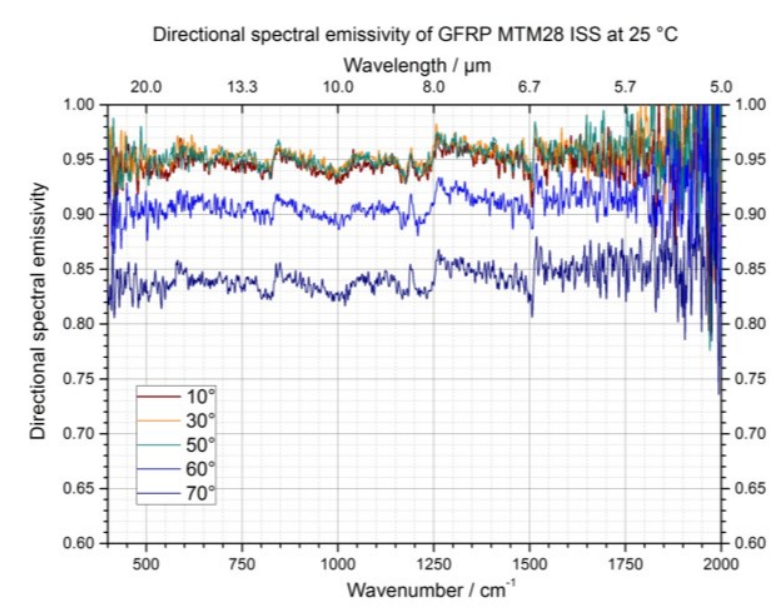

a)

Fig. 2. a) Directional spectral emissivity of GFRP MTM28 at $25^{\circ} \mathrm{C}$ under angles of observation from $10^{\circ}$ to $70^{\circ}$. b) Directional spectral emissivity of CFRP SE84 at $25^{\circ} \mathrm{C}$ under angles of observation from $10^{\circ}$ to $70^{\circ}$.

\section{Thermographic investigations during and after tensile load}

\subsection{Experimental set-up}

The tensile load tests were performed using a testing machine with a maximum tensile load of $100 \mathrm{kN}$. The test specimen was fixed at both ends (see figure 3.a) and the load was introduced quasi-static and for most of the tested coupons until failure with crosshead speed of $0.5 \mathrm{~mm} / \mathrm{s}$. Two IR cameras were positioned at the front side (side without notch) and at the back side (side with notch) of the test specimen for recoding the temperature during the test simultaneously, see figure 3.b. The IR camera at the front side has an MCT detector with a size of $640 \times 512$ pixels used at half frame $(320 \times 512)$, a nominal thermal resolution of $60 \mathrm{mK}$ at $30^{\circ} \mathrm{C}$, a lens with a FOV of $5.9^{\circ} \times 4.7^{\circ}$, a frame rate of $50 \mathrm{~Hz}$, an integration time of $140 \mu \mathrm{s}$, and was positioned at a distance of $120 \mathrm{~cm}$ to the sample. Thus, the spatial resolution per pixel was equal to $0.19 \times 0.19 \mathrm{~mm}^{2}$. The IR camera at the back side has an InSb detector with a size of $640 \times 512$ pixels, a nominal thermal resolution of $20 \mathrm{mK}$ at $30^{\circ} \mathrm{C}$, a lens with a FOV of $5.5^{\circ} \times 4.4^{\circ}$, a frame rate of $50 \mathrm{~Hz}$, an integration time of $1.2 \mathrm{~ms}$, and was positioned at a distance of $130 \mathrm{~cm}$ to the sample. Thus here a spatial resolution of $0.20 \times 0.20 \mathrm{~mm}^{2}$ was obtained.

The load-displacement diagrams of the three GFRP test specimens AFPD, 1AFPC and 2AFPC with thicknesses of $3.2,5.0$, and $5.0 \mathrm{~mm}$ and with remaining wall thicknesses at the notches of $1.7,3.5$ and $1.6 \mathrm{~mm}$, respectively, are shown in figure 3.c. Test specimens AFPD and 2AFPC with nearly similar remaining cross sections were loaded up to $20 \mathrm{kN}$ and 1 AFPC up to $45.2 \mathrm{kN}$. In all cases, the load was increased monotonously until a deviation from the linear displacement was observed. By considering the different cross sectional areas to which the load was introduced, these loads are belonging to failure tensile stresses of $196 \mathrm{MPa}$ for test specimen AFPD, of $208 \mathrm{MPa}$ for test specimen 2AFPC and of $215 \mathrm{MPa}$ for test specimen $1 \mathrm{AFPC}$.

The load displacements diagrams of the three CFRP test specimens AFMF, 1AFMG and 2AFMG are not shown here, but are similar to those of the GFRP test specimens with slightly different maximum loads. Test specimens AFMF and 2AFMG were loaded up to $18.3 \mathrm{kN}$ (235 MPa and $171 \mathrm{MPa}$, respectively) and $1 \mathrm{AFMG}$ up to $32 \mathrm{kN}$ (213 MPa).

After the tensile load, the GFRP and CFRP test specimens were investigated with active thermography. First, flash excitation was performed by using four flash lamps with an energy consumption of $6 \mathrm{~kJ}$ each at a distance of $40 \mathrm{~cm}$ to the front side of the samples leading to a heat flux density of $1.7 \mathrm{~J} / \mathrm{cm}^{2}$. Second, impulse excitation was performed for $10 \mathrm{~s}$ using an IR radiator with a power consumption of $2.4 \mathrm{~kJ}$. For achieving a homogeneous heating, the radiator was moved directly in front of the test specimen. For recording the temperature distribution as a function of time after heating, in each case an InSb IR camera with a detector size of $1240 \times 1024$ pixels, an integration time of $640 \mu \mathrm{m}$ at a frame rate of $50 \mathrm{~Hz}$, and a lens with a FOV of $21.7^{\circ} \times 17.5^{\circ}$ was used at a distance of $65 \mathrm{~cm}$ to the sample. Thus again a spatial resolution of $0.20 \times 0.20 \mathrm{~mm}^{2}$ per pixel was achieved. 
a)
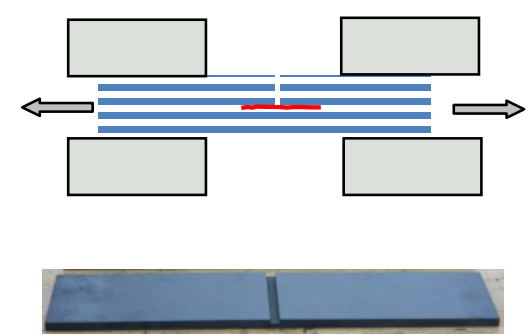

b)

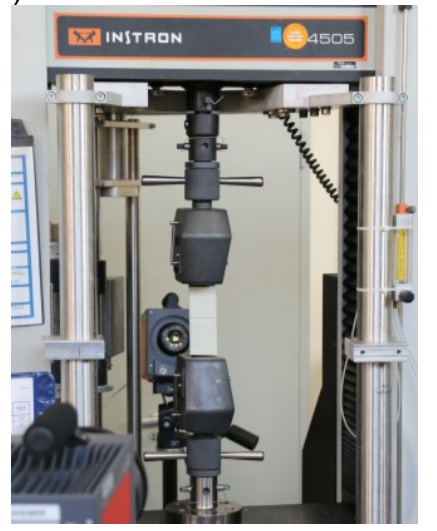

c)

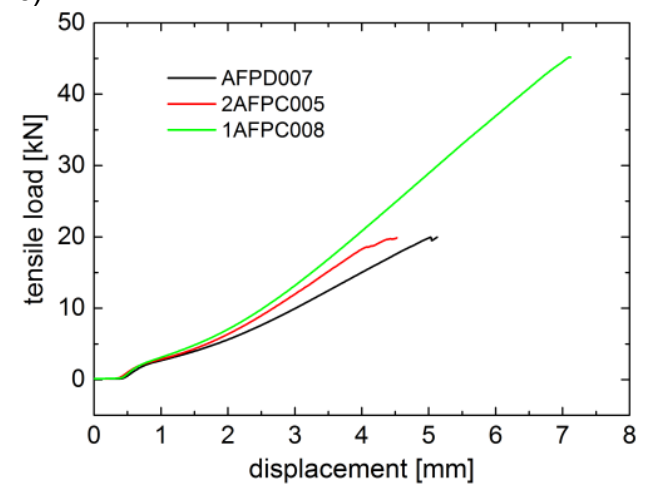

Fig. 3. a) Principle of tensile load tests at GFRP and CFRP test specimens with notches. b) Testing machine for tensile load with test samples with two IR cameras positioned at the front and back side of the test specimen (view from the backside, so the notch can be seen). c) Tensile load as a function of displacement for the three GFRP test specimens with notches at different depth.

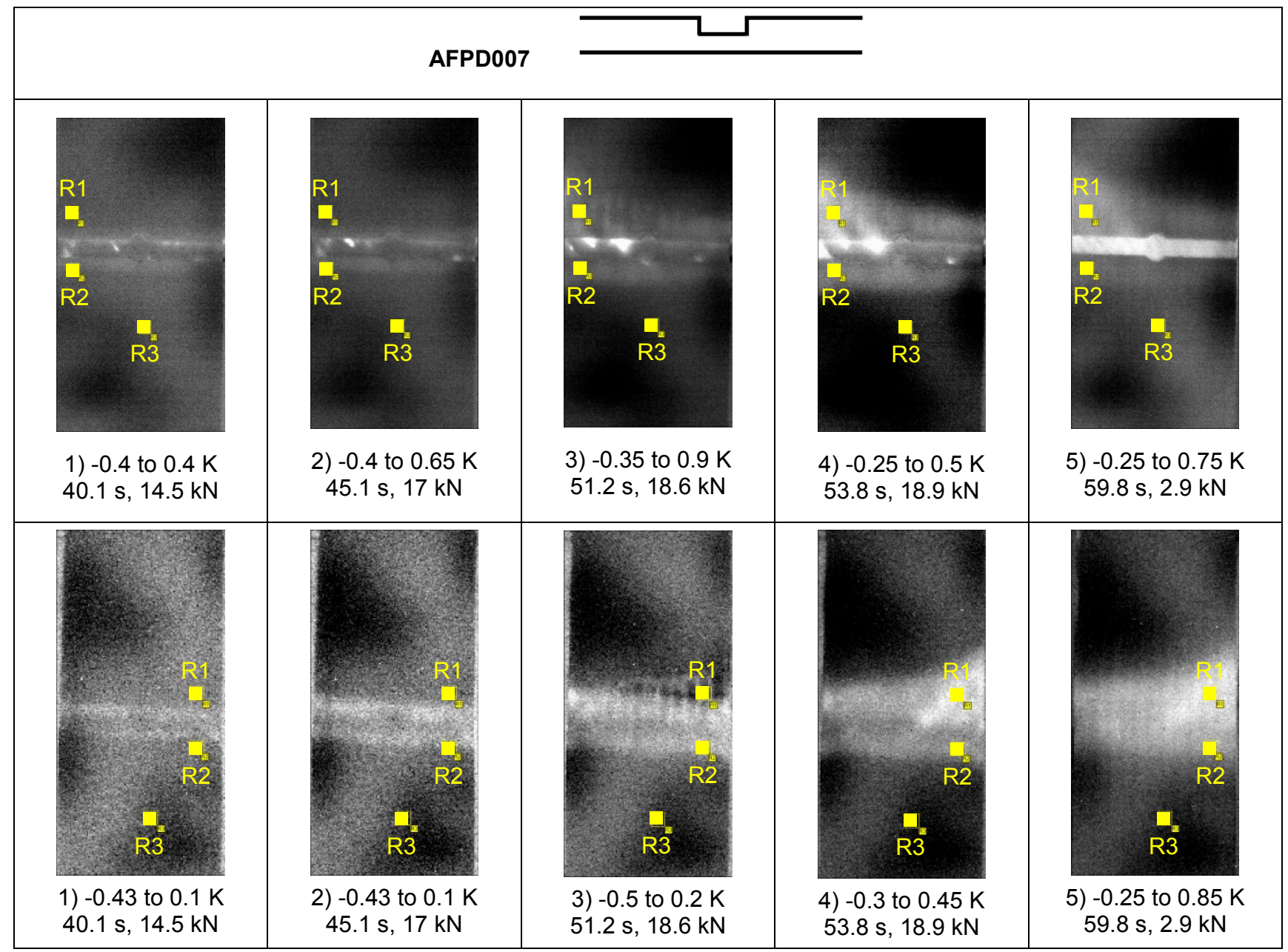

Fig. 4. Thermograms of the back (top) and front side (bottom) of GFRP test specimen AFPD007 with a thickness of $3.2 \mathrm{~mm}$ and a remaining wall thickness of $1.7 \mathrm{~mm}$ at the notch recorded at different times during tensile load. The sample failed after $50 \mathrm{~s}$. The time stamps of the thermograms are related to figure 6, left column. Each thermogram was scaled individually. Below each image, the temperature range from black to white on a linear grey scale is given. 


\subsection{Results during tensile load}

The thermograms recorded at both sides of the three GFRP test specimens during the tensile load are displayed in figure 4 (AFPD007) and figure 5 (1AFPC008 and 2AFPC005). For each surface of each test specimen, three areas consisting $20 \times 20$ pixels and thus having a size of about $4 \times 4 \mathrm{~mm}^{2}$ were selected where the temperature was averaged and was depicted as a function of time, see figure 6 . Area R1 was positioned above the notch and area R2 below the notch. Both areas were relatively close to the notch at distances between 1 and $3 \mathrm{~mm}$. Area R3 was located in an undamaged area below the notch at larger distance. In addition, all diagrams in figure 6 contain the tensile load as a function of time.

At the back side of test specimen AFPD007 in figure 4 top (side of the notch), short stripe shaped hot spots are appearing at lower loads (thermogram no. 1 and 2) which can be related to single fibre cracks. The stripes had an orientation of $-45^{\circ}$. Additionally, at this side already before failure two wider warm stripes around the edges of the notch could be observed. The sample failed after a time of $50 \mathrm{~s}$ at a load of $20 \mathrm{kN}$. The thermograms recorded afterwards (no. 3 to 5) show a warming up of a damaged (probably partly delaminated) area above and below the notch. At one of the lateral sides of the test specimen, the warmer area was wider than on the other one. The shape of this area was not symmetrically to the notch. In the last thermogram, the bottom of the notch is appearing considerably warmer than the surface of the sample. At the front side of the sample (figure 4 bottom), at lower loads two warm stripes could be recognized at the position of the edges of the notch. After failure, a warming up of the damaged area could be observed, too. This area has the same shape as at the back side.

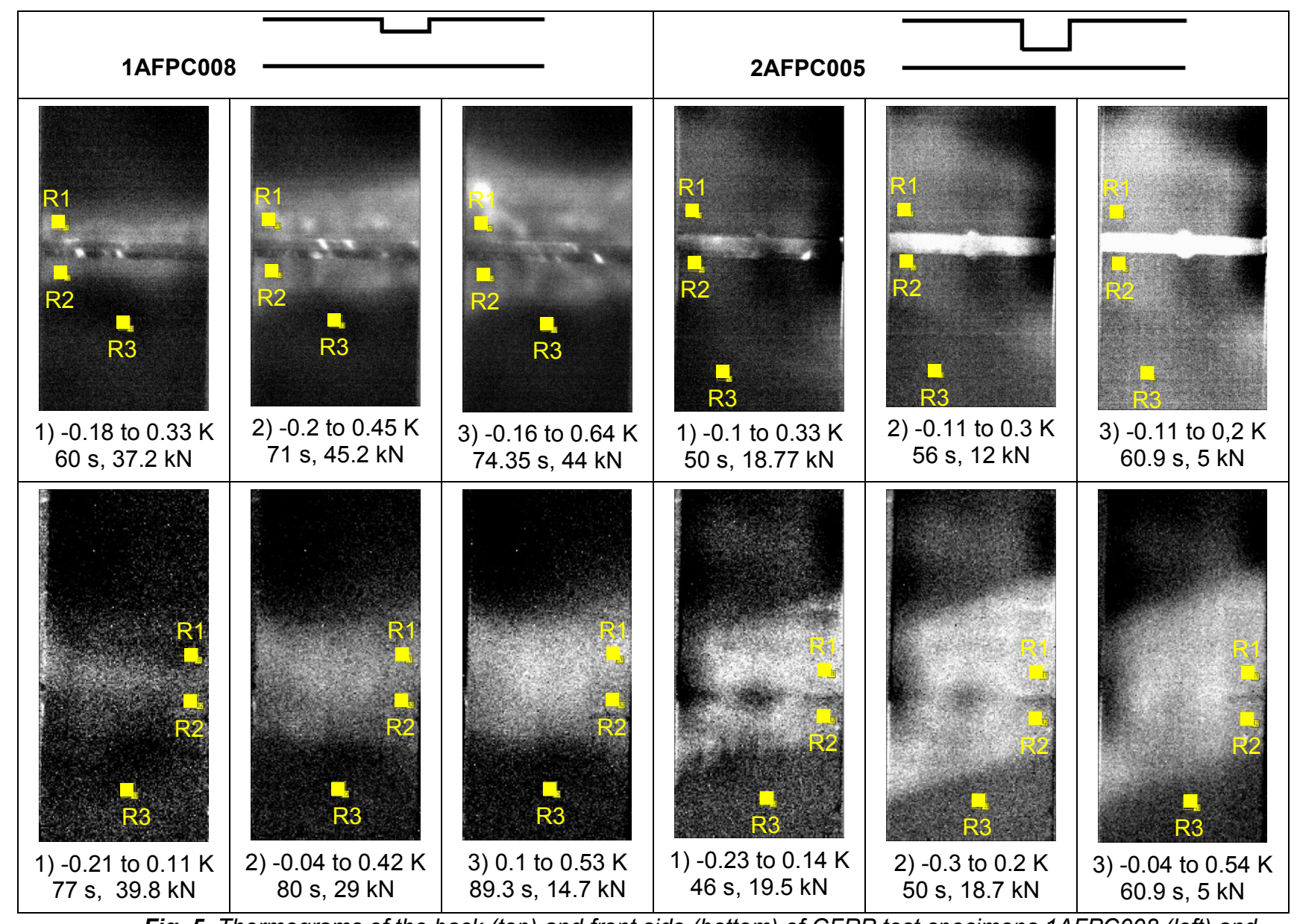

Fig. 5. Thermograms of the back (top) and front side (bottom) of GFRP test specimens 1 AFPC008 (left) and

$2 A F P C 005$ (right) with a thickness of $5 \mathrm{~mm}$ and a remaining wall thickness of $3.5 \mathrm{~mm}$ and $1.6 \mathrm{~mm}$ at the notches, respectively, recorded at different times during tensile load. Sample 1AFPC008 failed after 71 s, sample $2 A F P C 005$ after $45 \mathrm{~s}$. The time stamps of the thermograms are related to figure 4 , middle and right column.

The thermograms of test specimen 1AFPC008 are shown in figure 5 left. This test specimen failed after $71 \mathrm{~s}$ at a load of $45.2 \mathrm{kN}$. Through the whole load cycle, a lot of hot spots were observed related to fibre breaking. Again, two warmer stripes appeared at the edges of the notch. After failure, a large warm area appeared which can be related to delaminations. This area is larger as that of AFPD007, but has the same asymmetry (being wider at one of the lateral sides of the test specimen). Similar to AFPD007, the bottom of the notch appeared warmer at the end of the test (not shown here). At the front side (see figure 5 left, bottom), an increase of surface temperature could only be observed after 


\subsection{1/qirt.2016.076}

failure (please note the different time stamps). At the end of the sequence, the area with enhanced temperature has the same shape as at the back side.

Figure 5 right shows the thermograms of test specimen 2AFPC005, which failed after $45 \mathrm{~s}$ at a load of $20 \mathrm{kN}$. Here, only the thermograms after the failure are shown, as the temperature increase of the area with damage could only be observed after damage. This temperature increase was higher at the front side being closer to the delaminations. The warm damaged area has the shape of a parallelogram, thus the shape was different from the other test specimens. It appeared to be point symmetrically to the middle of the notch. During loading, fewer hot spots due to fibre cracking could be overserved in comparison to the other test specimens.

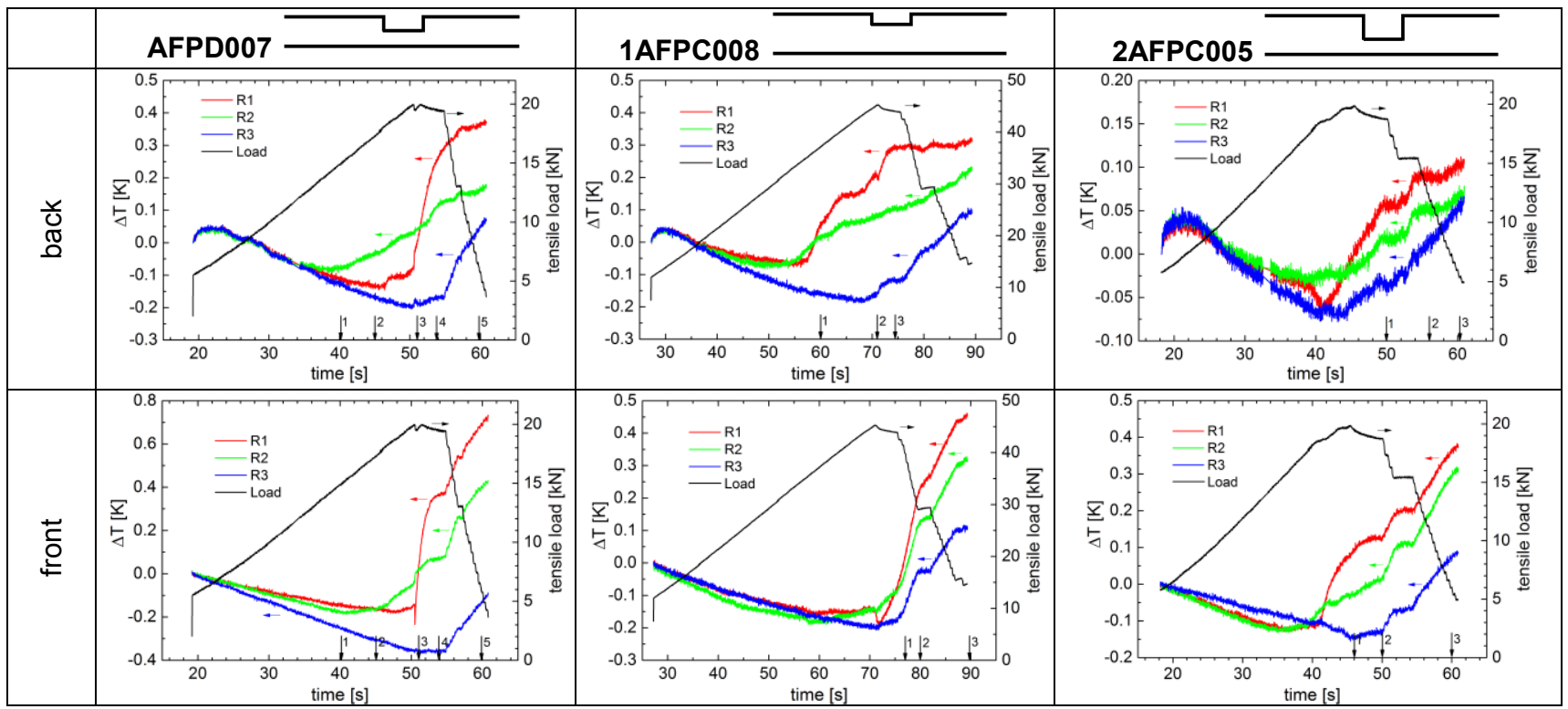

Fig. 6. Temperature (red, green and blue lines) and tensile load (black line) as a function of time during tensile load of the three GFRP test specimens. The three temperatures lines are belonging to different positions on the samples, which are marked in figure 5 and 6 , and were recorded at the back (top) and front side (bottom).

By comparing the temperature as a function of time diagrams in figure 6 , the following points can be summarized:

- In all diagrams a cooling down of the surface of the test specimens due to the thermo-elastic effect with increasing time and thus increasing load and displacement could be observed [9, 10]. Especially for the non-damaged area R3, the cooling down occurred until the failure of the samples.

- A temperature increase due to plastic deformation first starts at area R2 for all samples and always before failure. Afterwards, the temperature at area R1 rises relatively fast before failure at test specimens 1AFPC008 and 2AFPC005 and at the moment of failure at test specimen AFPD007. After the failure, also the temperature at area R3 was rising, but always with a delay in comparison to areas R1 and R2.

- At area R1 always the highest temperature rise, at R2 a medium temperature rise, and at R3 the lowest temperature rise was observed.

- At test specimen AFPD007, the temperature rises at the back and front surfaces were observed at the same time. This leads to the conclusion that the first damages are occurring at the middle of the sample, i. e. at the depth of the notch. The temperature increase at the front surface was higher and shows a second step in comparison to the temperature rise at the back surface. Probably further damages (and most probably partial delaminations) positioned closer to the front side occurred later during failure.

- At test specimen 1AFPC008, the temperature rise at the front side occurred considerably delayed to the temperature rise at the back side. Thus the delaminations might be positioned much closer to the back side (with the open notches) according to the position of the bottom of the notch. Again, the temperature increase at the front side was slightly larger than at the back side, probably due to further later damages located closer to the front side.

- At test specimen 2AFPC005, the temperature rise at the front side appeared slightly earlier than at the back side, again according to the position of the bottom of the notch, which was now closer to the front side. The temperature increase at the back side was much lower than at the front side. 


\subsection{Results after tensile load}

Although damages probably related to delaminations could be observed by warmed up areas during the tensile load, no clear sharp delaminations could be recognised by looking at the lateral side of the samples after load. In a few cases, some short white lines at different depths could be seen. In figure 7, the results obtained at the GFRP test specimens from investigations after tensile load are summarized. The first row (a) shows photos from the samples. For test specimens AFPD007 and 2AFPC005, these were obtained from the front side. For test specimen 1AFPC008, the photo could only be taken from the back side (side with the notch), as the front side was already blackened. For all samples, the damages and probably partly delaminated areas could be seen as lighter areas having a good contrast against the undisturbed translucent areas. The shapes of the light areas are very similar to those of the warmed up areas recorded during load in figures 4 and 5.

\begin{tabular}{|c|c|c|c|}
\hline & AFPD007 & $1 \mathrm{AFPC008}$ & 2AFPC005 \\
\hline \multirow[t]{2}{*}{ a) } & & & \\
\hline & photo & photo & hoto \\
\hline b) & & \multirow{2}{*}{ No data available } & \\
\hline & $\begin{array}{c}\text { thermogram } 0.95 \text { to } 1.65 \mathrm{~K} \\
1.2 \mathrm{~s} \text { after flash, without blackening }\end{array}$ & & $\begin{array}{c}\text { thermogram } 0.85 \text { to } 1.5 \mathrm{~K} \\
1.2 \mathrm{~s} \text { after flash, without blackening }\end{array}$ \\
\hline \multirow[t]{2}{*}{ c) } & & & \\
\hline & $\begin{array}{c}\text { thermogram } 1.7 \text { to } 2.6 \mathrm{~K} \\
5.6 \mathrm{~s} \text { after flash, with blackening }\end{array}$ & $\begin{array}{c}\text { thermogram } 0.4 \text { to } 1.2 \mathrm{~K} \\
35 \mathrm{~s} \text { after flash, with blackening }\end{array}$ & $\begin{array}{c}\text { thermogram } 1.7 \text { to } 2.6 \mathrm{~K} \\
5.6 \mathrm{~s} \text { after flash, with blackening }\end{array}$ \\
\hline \multirow[t]{2}{*}{ d) } & & & \\
\hline & $\begin{array}{c}5.4 \text { to } 8.4 \mathrm{~K}, 4.1 \mathrm{~s} \text { after heating of } \\
10 \mathrm{~s} \text { with an IR radiator }\end{array}$ & $\begin{array}{c}3.1 \text { to } 4.2 \mathrm{~K}, 19.6 \mathrm{~s} \text { after heating of } \\
10 \mathrm{~s} \text { with an IR radiator }\end{array}$ & $\begin{array}{c}1 \text { to } 19 \mathrm{~K}, 4.1 \mathrm{~s} \text { after heating of } 10 \mathrm{~s} \\
\text { with an IR radiator }\end{array}$ \\
\hline
\end{tabular}

Fig. 7. Results of active thermography at the three damaged GFRP test specimens. a) Photos of the damaged test specimens. b) Thermograms recorded after flash excitation without blackening of the samples. c) Thermograms recorded after flash excitation with blackening of the samples. d) Thermograms recorded after heating the blackened samples for $10 \mathrm{~s}$ with an infrared radiator. The temperature values below the thermograms are indicating the minimum and maximum temperature values related to a linear grey scale from black to white.

\begin{tabular}{|l|c|c|c|}
\hline & AFMF005 & 1AFMG007 & PAFMG007 \\
\hline a) & Photo & Photo & \\
\hline b) & 1.7 to $5.4 \mathrm{~K}, 0.72 \mathrm{~s}$ after flash & 0.65 to $1.5 \mathrm{~K}, 5.3 \mathrm{~s}$ after flash & 2 to $4 \mathrm{~K}, 0.74 \mathrm{~s}$ after flash \\
\hline
\end{tabular}

Fig. 8. Results of active thermography at the three damaged CFRP test specimens. a) Photos of a section of the lateral side of the damaged test specimens, the scale was enlarged in depth direction. b) Thermograms recorded after flash excitation without blackening of the samples. The temperature values below the thermograms are indicating the minimum and maximum temperature values related to a linear grey scale from black to white.

In figure 7.b, the thermograms recorded $1.2 \mathrm{~s}$ after flash excitation are shown for the non-blackened samples. As test specimen 1AFPC008 was already blackened, these data are not available. The damaged areas could be seen again as warmer areas with the same shape as in the photos and during tensile load. Here, the damages act as an 


\subsection{1/qirt.2016.076}

additional absorbing layer within the partially translucent material leading to heat dissipation in the related plane inside the material.

After blackening of the samples, the measurements with flash excitation were repeated, see figure 7.c. Due to the blackening, the flash was mainly absorbed at the surface that was heated up. From the surface, the heat was diffusing in transversal direction and was accumulating at inhomogeneities with lower effusivity. In the thermograms, only the notches could be seen as warmer areas revealing that the penetration depth of the thermal excitation and the observation period were sufficient. But the damaged areas could not be detected. Therefore, the test samples were heated with the above described IR radiator for about $10 \mathrm{~s}$. The thermograms recorded $4.1 \mathrm{~s}$ and $19.5 \mathrm{~s}$ after the heating impulse are displayed in figure 7.d. Here, parts of the damaged areas could be detected, but still not the whole areas displayed in figure 7.a and 7.b.

In contrary to the GFRP test specimens, the CFRP test specimens show a very clear and defined delamination after tensile loading, which could be already detected by visual inspection of the lateral side, see figure 8.a. These photos show a clear separation of the material parallel to the surface at the depth of the bottom of the notch or slightly deeper. As the CFRP test samples are already black, a blackening of the surface was not required. In figure 8.b, thermograms recorded $0.7 \mathrm{~s}$ and $5.3 \mathrm{~s}$ after flash excitation of the front surface are displayed. The notch as well as the delamination could be detected clearly. In the thermogram of test specimen AFMF005, two delaminated areas with different temperatures are observed. This could be explained with delaminations at two different depths.

\section{Summary and Conclusion}

Test specimens made of GFRP and CFRP with natural defects were realized by milling a notch into the plate and by performing tensile load tests until failure of the structures. Thermographic investigations were performed first during tensile load for observing the spatial and temporal temperature distribution due to elastic and plastic deformations. After failure, active thermography was applied using flash lamps and an IR radiator for thermal excitation. Here, the intention was to detect the defects induced by the tensile loads afterwards.

The optical investigations showed that the GFRP samples without additional pigmentation showed some residual transmittance in the range from 1.3 to $2.8 \mu \mathrm{m}$ but no significant transmittance at wavelengths longer than 2.8 $\mu \mathrm{m}$. Therefore, for heating of the samples a surface blackening is required in cases were the heat absorption should occur mainly at the surface. In the wavelength range of the IR camera, the transmittance is not relevant.

During tensile load of the GFRP test specimens, at the beginning a cooling down of the sample surface was observed due to the thermo-elastic effect. At all test specimens, already before failure spatially limited temperature increases were observed mainly located near and within the notch. During and after failure, the damaged areas are appearing warmer than the surrounding. Steps in the temperature time curves are indicating that the damages are not only generated at once at the moment of failure, but also before and after failure. Indeed, the following observations are hints to a more complex damage generation than just a simple delamination at one depth:

- In case of test specimen AFPD007, the bottom of the notch was located at the middle of the test specimen, thus a similar temperature rise was expected at the back and front sides of the test specimen. Although the temporal behaviour of the temperature time curves was similar, the temperature rise at the front surface was higher than at the back surface.

- In case of test specimen 1AFPC008, the notch was shallow and indeed, it was observed that the temperature rise at the front side was considerably delayed to that one at the back side. Anyway, the temperature increase at the front side was higher than at the back side.

- At test specimen 2AFPC005, the depth of the notch was beyond the half thickness of the sample. Here, the temperature rise at the back side was slightly delayed, but much less than for test specimen 1AFPC008. Again, the temperature increase at the front side was higher than at the back side.

Photos of the translucent GFRP test specimens after damage and investigations with flash thermography of the non-blackened samples clearly show the shape of the damaged areas with an orientation parallel to the surface. The size and shape of these areas are similar to the areas with higher temperatures observed during tensile load. But visual inspection of the lateral side of the test specimens revealed that there was not a single delamination at one depth and no clear separation of layers. This was supported by the results of flash and impulse thermography investigations of the blackened samples. Here, no clear defects could be detected at the depth of the notches, thus the induced damages are not leading to a clear air gap or separation of single layers.

In contradiction to the GFRP test specimens, the tensile loaded CFRP test specimens display delaminations with layer separation at the depth of the bottom of the notch and slightly deeper. With flash excitation, these delaminations could be detected clearly. In future publications, the temperature evolution during tensile load between different GFRP and CFRP test specimens will be compared.

Therefore, it can be concluded that the intended generation of artificial damages in GFRP and CFRP using tensile loads was successful, but the nature of damages seems to be not the same for both material classes. The partially optical translucence of some FRP has to be considered when thermographic results are discussed.

Further investigations of these GFRP and CFRP test specimens and the test specimens listed in table 1 with ultrasonics, shearography and microwaves (here only GFRP test specimens) are planned. It is expected that this would reveal additional information about depth and transversal distribution of the different damages. 


\section{Acknowledgements}

We gratefully acknowledge the help of K. Matzak, BAM 5.2, for performing the tensile load tests. The EMRP project is jointly funded by the EMRP participating countries within EURAMET and the European Union under the project no. ENG57 VITCEA.

\section{References}

[1] VITCEA Validated Inspection Techniques for Composites in Energy Applications, http://projects.npl.co.uk/vitcea/

[2] Kordatos, E. Z., Dassios, K. G., Aggelis, D. G., Matikas, T. E. Rapid evaluation of the fatigue limit in composites using infrared lock-in thermography and acoustic emission. Mechanics Research Communications 54 (2013), pp. $14-20$

[3] Munoz, V., Vales, B., Perrin, M., Pastor, M.-L., Welemane, H., Cantarel, A., Karama, M. Damage detection in CFRP by coupling acoustic emission and infrared thermography. Composites Part B: Engineering, 85 (2016) pp. 68-75.

[4] Goidescu, C., Welemane, H., Garnier, C., Fazzini, M., Brault, R., Péronnet, E., Mistou, S., Damage investigation in CFRP composites using full-field measurement techniques: Combination of digital image stereo-correlation, infrared thermography and X-ray tomography. Composites Part B: 48 (2013) 95-105

[5] Meola, C., Boccardi, S., Carlomagno, G.M., Boffa, N.D., Monaco, E., Ricci, F. Nondestructive evaluation of carbon fibre reinforced composites with infrared thermography and ultrasonics. Composite Structures 134 (2015) pp. 845-853

[6] Harizi, W., Chaki, S., Bourse, G., Ourak, M. Mechanical damage assessment of glass fibre-reinfirced polymer composites using passive infrared thermography. Composites: Part B 59 (2014), pp. 74-79

[7] Libonati, F., Vergani, L. Damage assessment of composite materials by means of thermographic analyses. Composites: Part B (2913) pp. 82-90.

[8] Monte, C. and Hollandt, J. The Measurement of Directional Spectral Emissivity in the Temperature Range from $80^{\circ} \mathrm{C}$ to $400^{\circ} \mathrm{C}$ at the Physikalisch-Technische Bundesanstalt. High Temperatures - High Pressures, 39, (2010), 151-164

[9] Chrysochoosa, A. Infrared thermography applied to the analysis of material behavior: a brief overview. QIRT Journal Vol. 9, Issue 2, 2012, 193-208

[10] Dumoulin, S., Louche, H., Hopperstad, O.S., Børvik, T. Heat sources, energy storage and dissipation in highstrength steels: Experiments and modelling. European Journal of Mechanics - A/Solids Vol. 29, Issue 3, 2010, pp. $461-474$ 